\title{
Nucleated Suburbanisation in a Competitive Market Economy*
}

\section{John R. Miron}

Land-use planners in many market economy countries have been intrigued by the possibility of creating suburbs which are spatially distinct from each other and from their metropolitan cores. Policies have been promoted in this regard to protect large-scale 'green areas' which might act partly as a visible buffer or separator between urban areas throughout a metropolitan region. Various benefits have been suggested by different proponents of this 'nucleated suburbanisation' and large-scale greenarea preservation. These have included the preservation of valuable farm land or historical areas, the provision of recreation land in close proximity to urban residents, flood protection, the retention of distinctive small communities, the separation of non-complementary urban land uses, and the systematic, rational development of regional infrastructure servicing schemes.

The most direct means of implementing nucleated suburbanisation is through legislation. Typically, a planning agency identifies areas in which urban growth is to be either encouraged or limited. In those areas in which it is deemed desirable to limit or prevent growth, legislation is introduced which arbitrarily removes or restricts the development rights of local property owners. Subsequent new urban development in the region is then forced to locate in those nucleated areas where growth is to be encouraged. Sometimes, incentives of one kind or another are also provided to make these locations more attractive to households and firms.

The use of legislative controls over land use and development is not without problems in societies where the real property rights of individuals are constitutionally or historically protected. In these cases, compensation is often demanded and sometimes paid. In addition, the taking of real property rights is sometimes seen by citizens in general as a very serious and undesirable action. To resolve this problem with legislative controls,
[First received July 1977; in final form November 1977]

some planners have resorted to two alternative approaches. The first has been to find methods of indirectly compensating for the taking of property rights. ${ }^{1}$ The second has been to look at the possibility of encouraging nucleated suburbanisation without resorting to legislative control. This paper is directed to a discussion of some aspects of the feasibility of the latter approach.

There have been at least three alternative ways proposed to encourage voluntary nucleated suburbanisation. In describing these, it is assumed that a planning agency has already, for whatever combination of reasons outlined above, identified some spaces as green areas and others as development areas. The first alternative approach would be to provide direct subsidies to current land users in green areas sufficient to help them avoid being displaced by potential urban users. ${ }^{2}$ The second alternative is to make urban development in green areas unattractive by designing regional servicing schemes such as limited access roads which discriminate in favour of the nucleated development areas. The final alternative is to create viable new suburban centres sufficiently far from other areas in the metropolitan region to ensure the opening up of intervening green areas.

The purpose of this paper is to explore in particular some economic issues related to the viability of the third alternative. A spatial equilibrium framework provides a method of systematic evaluation for the alternatives and is used to generate interesting marginal conditions governing the viability of alternative non-legislative approaches. The paper is concluded with an assessment of the viability of this approach.

\section{An Analytical Framework}

A spatial equilibrium framework of the Alonso-Muth variety is a restrictive but useful way of analysing the

The author is Assistant Professor of Geography at Scarborough College, University of Toronto, West Hill, Ontario, MIC 1A4, Canada.

* An earlier version of this paper was undertaken while the author was associated with the International Institute for Applied Systems Analysis, A-2361 Laxenburg, Austria.

1 One of these approaches, for example, involves the concept of Transferable Development Rights. Field and Connad (1975) outline some issues involved in this approach.

2 Goldberg and Heaver (1970) investigate some of the economic problems in evaluating how much and when to purchase land for multi-use corridors which might serve to preserve green areas. 
existence of nucleated suburbs. An Alonso-Muth model can be used to generate spatial patterns of Ricardian land rents and land use in long-run equilibrium. In the short run, to translate these into the locational patterns of households or firms would require an understanding of imperfections in the land market and of disequilibrium dynamics. Some critics would argue that these latter considerations are among the most important determinants of contemporary locational behaviour. While not denying the significance of these arguments, emphasis is here placed only on locational patterns in long-run equilibrium. Although using an Alonso-Muth approach is of necessity a partial analysis, the derived long-run behaviour does provide some guides to behaviour in the shorter run.

To begin, an elementary 'closed' spatial equilibrium model is assumed. ${ }^{3}$ The basic assumptions used are the following:

(i) There exists two sets of actors; land-owners and residents.

(ii) There are a large number of land-owners and each

(a) owns a relatively small parcel of land,

(b) attempts to maximise the rent received from that parcel,

(c) is non-collusive, and

(d) lives and disposes of his rental income outside the region.

(iii) There are $N$ residents and each

(a) earns the same income (Y),

(b) works at the same central location (C).

(c) has the same log-linear utility function, $U$, defined over consumption of two goods, land (L) and other goods $(\mathrm{X})$, each with positive income preferences,

(d) maximises $U$ subject to a budget constraint,

(e) is free to choose any residential site,

(f) is non-collusive.

(iv) The composite good $\mathrm{X}$ is uniformly available at a fixed price, $P_{\mathrm{x}}$.

(v) Commuting costs exist and are proportional to distance. The cost per round-trip kilometre is assumed to be ' $c$ '.

(vi) The urban land market is

(a) competitive in that land is allocated to the highest bidder which is either a resident or some nonurban land use offering a fixed rent, $R_{\mathrm{a}}$, everywhere

(b) in long-run equilibrium such that no resident or landlord would be better off by a switching of landlord-tenant assignments.

These assumptions are typically sufficient to generate a set of equilibrium bid rents for land which decrease monotonically with distance from C. As is well known, the rate of decrease of rents with distance will reflect the marginal rate of substitution between land and the composite other good. Whatever this rate of substitution, the monotonically declining bid rents of residents together with the fixed bid rent of the non-urban use are sufficient to ensure that (i) all residents will reside within some finite maximum distance, $s_{\mathrm{C}}$, from $\mathrm{C}$ and (ii) no land will be allocated to the non-urban use at distance $s$, where $s<s_{c}$. As indicated in Fig. 1, this occurs because the equilibrium bid rent function of residents, $R(s)$, will be greater than or equal to $R_{\mathrm{a}}$ for $s<s_{\mathrm{C}}$ and less everywhere else. Thus, non-urban land uses will not occur within the city defined by this model.

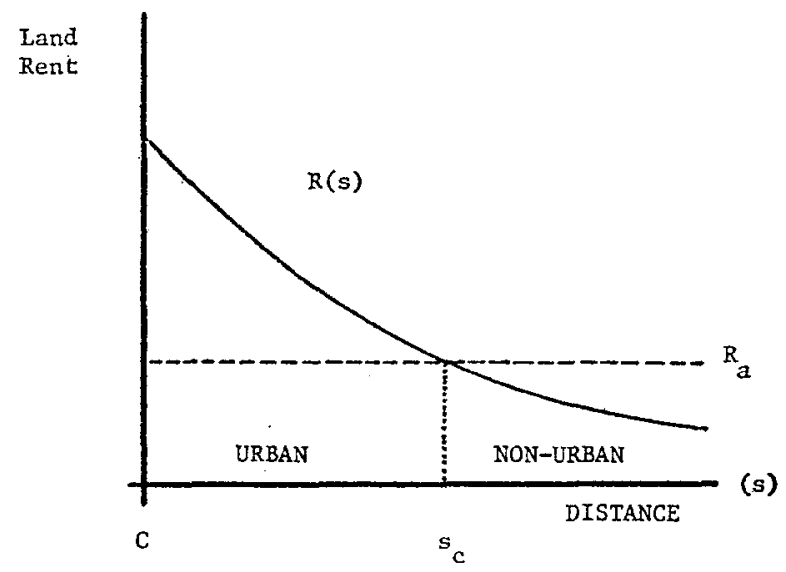

Fig. 1. Equilibrium land rents and the urban boundary.

In a closed model of spatial equilibrium, there is a positive correspondence between the Ricardian rent at any location and city size $N$. As $N$ increases, two adjustments take place. The physical area of the city increases (i.e., $s_{\mathrm{c}}$ increases) and the equilibrium land rent function, $R(s)$, shifts upward. The two changes are complementary since the rent at the new boundary must be $R_{\mathrm{a}}$ so that at the old boundary and elsewhere rents must increase to preserve the equilibrium. ${ }^{4}$ An example in which the number of residents increases from $N_{1}$ to $N_{2}$ is illustrated in Fig. 2. With other parameters fixed, there is an additional implication that utility levels fall as $N$ increases. ${ }^{5}$

\section{Alternative Policy Tools}

Consider a public agency which is trying to encourage voluntary nucleated suburbanisation via the third strategy outlined in the introduction. If an agency were to follow this strategy alone, it would attempt to create at a designated sub-centre something which would attract residents. This attraction might range from jobs to some unique sub-centre amenity such as a planned environment or recreational facility. The agency would

3 The term 'closed' is attributable to Wheaton (1974) and indicates a model in which the population is fixed in size.

4 The growth of $N$ thus implies an increase in the density of residents unless the demand for land is totally price-inelastic. In general, only a portion of the growth in population will be accommodated at the urban fringe.

5 Wheaton (1974: pp. 228-229) discusses this aspect of the closed model in a general form. 


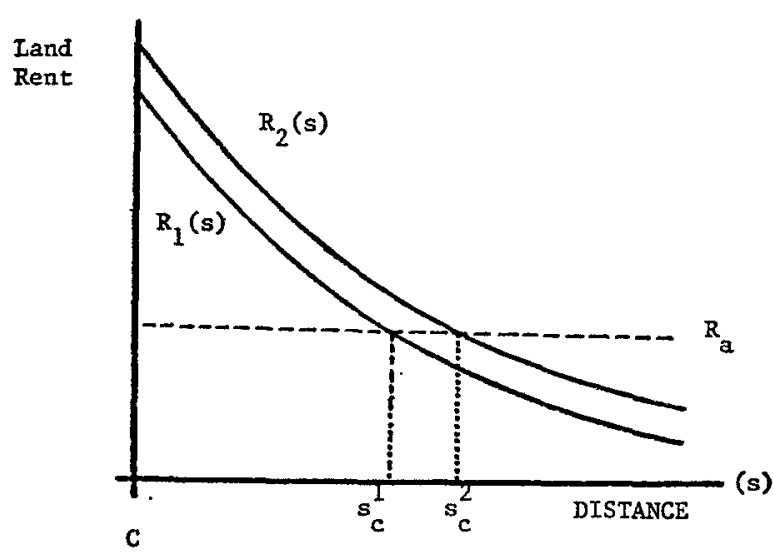

Fig. 2. Comparative statics of population growth.

hope that the sub-centre is attractive enough to pull a cluster of residences away from the inner metropolitan area taking development pressure off any nearby designated green area.

Two such attractions are considered here. One is the provision of jobs in the sub-centre itself. A model is presented in Section 3 which considers the locational choice problem of the suburban worker who is also attracted by central city amenities. The second is the provision of a unique amenity at the suburban locations. A model is presented in Section 4 which considers the locational choice problem of the central city worker who is attracted by this amenity. These two models share a similar mathematical structure and both yield interesting marginal conditions.

\section{A Suburban Model with Decentralised Employment}

\subsection{The Model Outlined}

Let us make the following changes to the assumption outlined in Section 2. First, replace assumption (iii) (b) by the following:

(iii) (b)' works at one of two points in space, $\mathrm{C}$ and $S$, which can be thought of as a central city and a suburban location respectively. Further, assume there are $N_{\mathrm{c}}$ and $N_{\mathrm{s}}$ jobs at the two locations respectively where

$$
N=N_{\mathrm{c}}+N_{\mathrm{s}}
$$

Secondly, replace assumption (iv) by

(iv) ${ }^{\prime}$ The composite good $\mathrm{X}$ is available only at $\mathrm{C}$. Both central city and suburban workers must travel to $\mathrm{C}$ to acquire this good.6 A separate trip is required for each unit of $\mathrm{X}$ consumed. Each unit of $\mathrm{X}$ is acquired at an f.o.b. price of $\boldsymbol{P}_{\mathbf{X}}$ plus a distanceproportional travel cost.7 For a resident at distance ' $r$ ' from $\mathrm{C}$, the 'delivered' or 'effective' price of a unit of $\mathrm{X}$ is $P[r]$ where

$$
P[r]=P_{x}+t r \quad t>0
$$

Finally, append a new assumption to those contained in Section 1.

(vii) Locations $\mathbf{C}$ and $\mathbf{S}$ are separated by a distance of ' $d$ ' kilometres. It is assumed that the cost of commuting $d$ kilometres or travelling that distance to purchase $\mathrm{X}$ does not exceed a resident's income, $\mathrm{Y}$.

$$
c d<\mathrm{Y} \text { and } t d<\mathrm{Y}
$$

Under the above assumptions, locational behaviour of the residents can now be examined. It is quickly apparent that the central city (or $\mathrm{C}-$ ) workers have the same equilibrium behaviour found in the elementary model. That is, they have an equilibrium bid rent function which declines monotonically with distance from $\mathrm{C}$ as in Fig. 1. The surburban (or $\mathrm{S}_{--}$) workers may behave differently, however, because they are attracted to both $\mathrm{C}$ and $\mathrm{S}$. It is the locational behaviour of $\mathrm{S}-$ workers which we shall now examine.

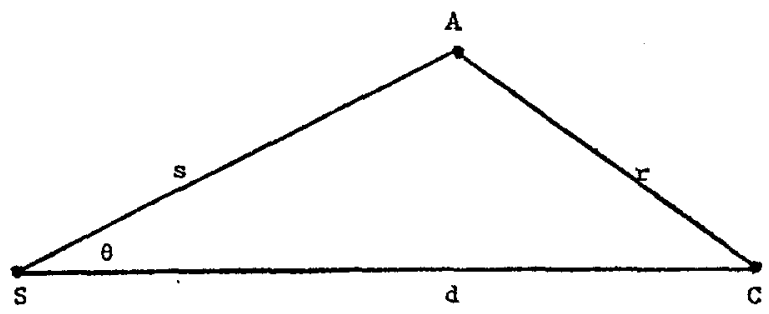

Fig. 3

The $\mathbf{S}$-worker selects a residential site keeping in mind its proximity to both $\mathrm{C}$ and $\mathrm{S}$. It is helpful to denote the location of a residential site in terms of its polar co-ordinates vis-a-vis $\mathbf{S}$ and $\mathrm{C}$. As illustrated in Fig. 3, consider a site $\mathrm{A}$ at ' $s$ ' kilometres from $\mathrm{S}$ and at an angle $\theta$ (measured from the $\mathrm{SC}$ ray). Site $\mathrm{A}$ will be $r[s, \theta]$ kilometres from $\mathrm{C}$ where 8

$$
r[s, \theta]=\left(d^{2}+s^{2}-2 d s \cdot \cos \theta\right)^{1 / 2}
$$

This site is desired if it permits the resident $\mathrm{S}$-worker to maximise his utility level given by 9

$$
\mathrm{U}=\mathrm{X}^{\alpha} \mathrm{L}^{1-\alpha} \quad 0<\alpha<1
$$

6 This altered characterisation of X need not reduce the generality of the original model. Another composite good (say Z), available everywhere at a uniform price, can be introduced without any significant theoretical effect on the remaining discussion. 7 The transporation cost component $(t r)$ corresponds to the Varaiya-Artle (1972) notion of 'transaction cost'.

8 Here, we restrict our discussion to locations between $\mathbf{C}$ and $\mathbf{S}$. In other words, it is assumed that $s . \cos \theta<d$.

9 The utility levels of $\mathrm{C}-$ and $\mathrm{S}$ - workers may be different from each other even though both share the same functional form (2). Utility differentials between the two groups may arise because of the difference between $N_{\mathrm{e}}$ and $N_{\mathrm{s}}$ even though prices and incomes are identical for both. 
Further, a budget constraint of the following form must be met.

$$
\mathrm{Y}=c s+R[s, \theta] \cdot \mathrm{L}+(P+t \cdot r[s, \theta]) \mathrm{X}
$$

Here $R[s, \theta]$ is the equilibrium rent per unit of land at $\mathrm{A}$.

\subsection{Solution of the Model}

Utility maximisation and spatial equilibrium conditions can now be defined. Maximising (2) with respect to X (or L), subject to (1) and (3), yields the familiar first order conditions

$$
\begin{aligned}
R[s, \theta] \cdot \mathrm{L} & =(1-\alpha)(\mathrm{Y}-c s) \\
(P+t \cdot r[s, \theta]) \cdot \mathrm{X} & =\alpha(\mathrm{Y}-c s)
\end{aligned}
$$

In addition, maximising $(2)$ with respect to location ( $s$ and $\theta$ ) yields some less-familiar first-order conditions.

$$
\begin{aligned}
c+\mathrm{L} \cdot \partial \mathrm{R} / \partial s+\mathrm{X} \cdot(\partial \mathrm{P}[r] / \partial s) & =0 . \\
\mathrm{L} \cdot \partial \mathrm{R} / \partial \theta+\mathrm{X} \cdot(\partial P[r] / \partial \theta) & =0 .
\end{aligned}
$$

In both cases, (6) and (7) indicate that a location $[s, \theta]$ is chosen where the marginal changes in total rent payments are exactly offset by the marginal changes in other costs. ${ }^{10}$ Of course, (6) and (7) can be used either to find a utility-maximising location given $R[s, \theta]$ or to find an $R[s, \theta]$ which makes $\mathrm{S}$-workers indifferent among all possible residence sites. Taking the latter approach, it can be shown that, for $\mathrm{S}$-workers, such an equilibrium bid rent functions is ${ }^{11}$

$$
R_{\mathrm{S}}[s, \theta]=\frac{\left(B / \widetilde{U}_{\mathrm{S}}\right)^{1 /(1-\alpha)}(Y-c s)^{1 /(1-\alpha)}}{\left(P_{\mathrm{X}}+t \cdot r\right)^{\alpha /(1-\alpha)}}
$$

where

$$
B=\alpha^{\alpha}(1-\alpha)^{1-\alpha}
$$

and $\tilde{U}_{\mathrm{s}}$ is the utility level achieved by $\mathrm{S}$-workers everywhere in the area.

A similar procedure can be used to find the equilibrium bid rent function of $\mathrm{C}$-workers. This yields

$$
R_{\mathrm{C}}[s, \theta]=\frac{\left(B / \tilde{U}_{\mathrm{C}}\right)^{1 /(1-\alpha)}(Y-c r)^{1 /(1-\alpha)}}{\left(P_{\mathrm{X}}+t r\right)^{\alpha /(1-\alpha)}}
$$

Here, $\tilde{U}_{\mathrm{c}}$ is the equilibrium utility level achieved by all $\mathrm{C}$-workers. The market equilibrium assumption (vi) (a) further asserts that the rent paid for a parcel of land at location $[s, \theta]$ is the larger of $(8)$ or $(9)$.

\subsection{Interpretation of the Model}

Several observations can be made about $R_{\mathrm{S}}[s, \theta]$. First, $\widetilde{U}_{\mathbf{s}}$ is as yet an unknown. Its value depends both on $N_{\mathrm{s}}$ and on the spatial pattern of bid rents of competing land uses. Secondly, although $\tilde{U}_{\mathrm{s}}$ is unknown, its value does not affect the relative rent bids of $\mathrm{S}$-workers for one location over another. The relative spatial pattern of rent bids is fixed in that the ratio of bid rents at any pair of locations is independent of $\tilde{U}_{\mathrm{s}}$. Thus, if we wish to investigate the relative shape of $R_{S}[s, \theta]$ over space, prior knowledge of $\tilde{U}_{\mathrm{s}}$ is unnecessary.

With these points in mind, let us investigate the shape of the $\mathbf{S}$-worker's bid rent function between $\mathbf{S}$ and $\mathbf{C}$. $R_{\mathrm{s}}[s, \theta]$ can take on a variety of three-dimensional shapes although it is symmetric about the SC ray. ${ }^{12}$ It may be [i] monotonically decreasing about $\mathrm{S}$, [ii] monotonically decreasing about $\mathrm{C}$, or [iii] U-shaped in some part of the space between $C$ and $S$. These three cases, which are illustrated in Fig. 4, have significantly different implications for nucleated suburbanisation. It is therefore important to establish the marginal conditions under which each shape of $R_{\mathrm{S}}[s, \theta]$ will occur.

One approach to evaluating the shape of $R_{\mathrm{S}}[s, \theta]$ is to enquire about stationary points between $C$ and $S$. From (6) and (7), it can be seen that $\partial R_{\mathrm{S}} / \partial s=0$ and $\partial R_{\mathrm{S}} / \partial \theta=0$ when

$$
\begin{aligned}
& c+x \frac{\partial P[r]}{\partial s}=0 \\
& s \cdot \sin \theta=0
\end{aligned}
$$

From (11), $\theta=0$ : that is, stationary points occur only on the SC ray. ${ }^{13}$ Substituting into (10) yields

$$
s^{*}=\frac{c\left(P_{\mathrm{X}}+t d\right)-\alpha t Y}{(1-\alpha) c t}
$$

where $\left[s^{*}, 0\right]$ is the location of a stationary point, if one exists, between $C$ and $S .14$ This stationary point exists, as illustrated by line [iii] in Figure 4, where $0<s^{*}<d$. If $s^{*}>d$, [i] occurs while if $s^{*}<0$, [ii] occurs.

Nucleated suburbanisation is most likely to occur if [i] in Fig. 4 is the appropriate bid rent function for S-workers. It is less likely to occur in the case of [iii] although it is still possible. In the case of [ii], nucleated suburbanisation is impossible. Some possible outcomes are illustrated in Fig. 5. There, a C-worker's bid rent function, $R_{\mathrm{C}}[s, 0]$, and the non-urban land use's bid rent, $R_{\mathrm{a}}$, are identified. Given a type [i] bid rent function, $R_{\mathrm{S}}^{\mathrm{i}}[s, 0]$, it is deduced that $\mathrm{S}$-workers located only around $\mathbf{S}$ reaching as close to $\mathrm{C}$ as $\left[s_{1}, 0\right]$. The space from

10 Commuting costs do not enter into (7) because these are independent of $\theta$.

11 In (8) and (9), the arguments of $r$ are omitted for each of presentation. The subscripts ' $c$ ' and ' $s$ ' are used to identify the bidrent function of each type of worker.

12 That is, $R_{1}(s, \theta)=R_{\mathbf{P}}[s, 2 \pi-\theta]$.

13 The alternative is $s=0$ but $R_{\mathrm{S}}(s, \theta)$ is not differentiable at this point.

14 Note that $\left(s^{*}, 0\right)$ is a saddle point when $\theta$ is variable. 


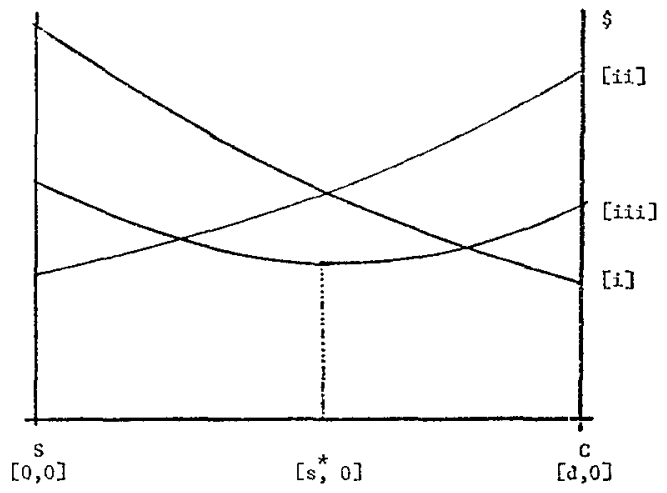

Fig. 4. Alternative $\mathrm{R}_{\mathrm{S}}(\mathrm{s}, \theta)$ bid rent functions along the $\mathrm{SC}$ ray.

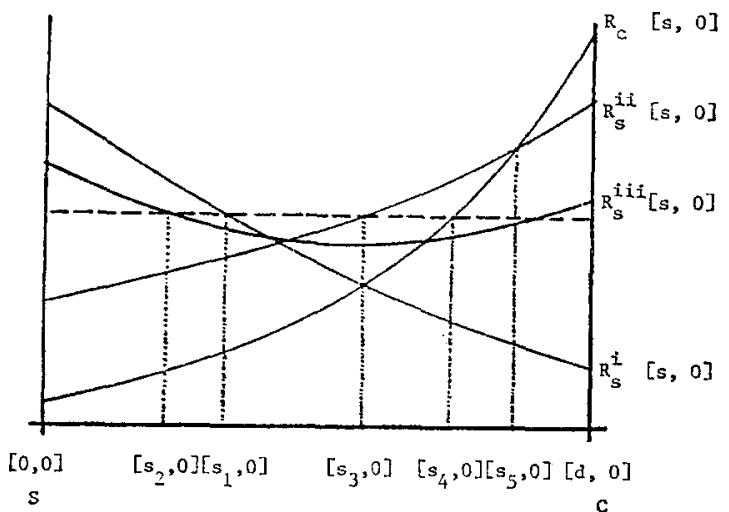

Fig. 5. Nucleated suburbanisation and the shape of $\mathbf{R}_{\mathrm{s}}(\mathrm{s}, 0)$ along the $S C$ ray.

$\left[s_{1}, 0\right]$ to $\left[s_{4}, 0\right]$ (where $R_{\mathrm{C}}[s, 0]$ and $R_{\mathrm{a}}$ intersect) would be reserved for the non-urban use while $\mathrm{C}$-workers would reside from $\left[s_{4}, 0\right]$ to $[d, 0]$. Given a type [ii] bid rent function, $R_{\mathrm{S}}^{\mathrm{ii}}[s, 0]$, the non-urban use would occupy from $[0,0]$ to $\left[s_{3}, 0\right], S$-workers from $\left[s_{3}, 0\right]$ to $\left[s_{5}, 0\right]$, and $\mathrm{C}$ - workers from $\left[s_{5}, 0\right]$ to $[d, 0]$. In this case, the suburb is spatially contiguous to the central city and nucleated suburbanisation cannot occur. In the final case of a type [iii] bid rent function, $R_{\mathrm{S}}^{\mathrm{iij}}$, the solution in Fig. 5 shows a nucleated suburb located around $S$ with a boundary reaching $\left[s_{2}, 0\right]$. This latter representation is just one of three possibilities; the others involve either some or all $\mathrm{S}$-workers locating adjacent to the $\mathrm{C}$-workers.

The marginal conditions for nucleated suburbanisation can now be established. To avoid type [ii] bid-rent functions, a necessary but not sufficient condition, it is required that $s^{*}>0$ or

$$
c>t\left[\frac{\alpha Y}{P_{\mathrm{X}}+t d}\right]
$$

The term in [] brackets is, from (5), the number of units of $\mathrm{X}$ (or trips to $\mathrm{C}$ ) consumed by an S-worker residing at $S$. Condition (13) asserts that the marginal cost of commuting one extra kilometre to work at $\mathbf{S}$ must be greater than the marginal cost of travelling one extra kilometre to $C$ to consume $X$ for the $S$ - worker living at $S$. Alternatively to ensure a type [i] bid rent function, a sufficient but not necessary condition, it is required that $s^{*}>d$ or

$$
c>t \frac{\alpha(\mathrm{Y}-c d)}{P_{\mathrm{X}}}
$$

This asserts that the marginal cost of commuting one extra kilometre to work at $\mathbf{S}$ must be greater than the marginal cost of travelling to $C$ to purchase $X$ for the S-worker residing at $C$. Thus, the only difference between (13) and (14) is the location at which the level of $\mathrm{X}$ consumption for an S-worker is measured. Both conditions assert that for nucleated suburbanisation to occur marginal job commuting costs to the suburban location must outweigh the marginal travel cost associated with shopping at $\mathrm{C}$.

\section{A Suburban Model with Local Amenities}

\subsection{The Model and Its Solution}

Consider now an opposite case where all employment remains centralised at $\mathbf{C}$ but where the suburb offers an amenity not found in the central city. The particular amenity thought of here is an infinitely long, linear beach. A point $S$ is identified as the closest point on the beach to $\mathrm{C}$ although the beach amenity can be equally enjoyed at any point along its length.

The assumptions of the elementary model are modified as follows. Replace assumption (iv) by

(iv) 'The composite good, $\mathrm{X}$, is uniformly available anywhere along the beach. Each unit of $\mathrm{X}$ consumed requires a separate trip. The cost of a beach trip $P(r)$ includes a fixed entry fee $\left(\boldsymbol{P}_{\mathbf{X}}\right)$ and a distanceproportional travel cost $t . r$ for the household located $r$ kilometres from the beach. 15

Also, assumption (vii) as outlined in Section 3.1 is invoked.

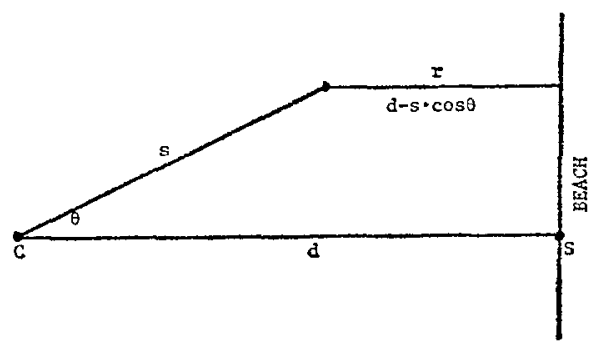

Fig. 6. Distances in the Suburban Amenities model.

15 The fixed entry fee might include the cost of lunches, sun-tan lotion, and parking fees for example. 
Each worker now selects a residential site keeping in mind its proximity to both $\mathrm{C}$ and the beach. It is helpful to use polar coordinates again and in Fig. 6, shortest distances to the beach are outlined for any site, $[s, \theta]$. Here, the distance to the point of 'purchase' of the beach amenity is

$$
r[s, \theta]=d-s \cdot \cos \theta
$$

Other than (15), the form of this model is identical to that in Section 3; maximise (2) subject to (3) and (15).

The solution to this model is also similar to that in Section 3. The first-order conditions are identical to (4), (5), (6) and (7). They yield an equilibrium bid rent function of the following form

$$
R[s, \theta]=\frac{(B / \tilde{U})^{1 /(1-\alpha)}(Y-c s)^{1 /(1-\alpha)}}{\left(P_{\mathrm{X}}+t d-t \cdot s \cdot \cos \theta\right)^{\alpha /(1-\alpha)}}
$$

where $\tilde{U}$ is the equilibrium utility level for any resident. In form, (16) differs from the bid-rent function of $S$ - workers only in terms of how ' $r$ ' is defined.

\subsection{Interpretation of the Model}

It is easily seen that $R[s, \theta]$ is very similar to $R_{\mathrm{S}}[s, \theta]$. It also takes on one of the three shapes illustrated in Fig. 4. The conditions for generating a stationary point $\left[s^{*}, 0\right]$ is identical to (12) as well.

The main difference between this model and that of Section 3 lies the phenomenon whose existence we are searching for. Here nucleated suburbanisation occurs when some residents choose to locate along the beach and some near $\mathrm{C}$. The solutions in which all residences choose to locate either at the beach or at $\mathrm{C}$ would thus not constitute nucleated suburbanisation.

A necessary condition for nucleated suburbanisation here is that $R_{\mathrm{S}}[s, 0]$ be U-shaped, or in other words, that $0<s^{*}<d$. This implies that

$$
t \frac{\alpha(Y-c d)}{P_{\mathrm{X}}}>c>t \frac{\alpha Y}{P_{\mathrm{X}}+t d}
$$

The other necessary conditions establishing sufficiency are that $R[0,0]>R_{\mathrm{a}}, R[d, 0]>R_{\mathrm{a}}$, and $R\left[s^{*}, 0\right]<R_{\mathrm{a}}$. Under all these conditions the equilibrium bid rent function of residents would be similar to that illustrated in Fig. 7 . There, some residences are clustered near $\mathbf{S}$ (or the beach in general) while others are clustered around $\mathrm{C}$. Along the $\mathrm{SC}$ ray, the space from $\left[s_{1}, 0\right]$ to $\left[s_{2}, 0\right]$ is occupied by the non-urban use.

What does (17) imply? The right and left-hand terms are the marginal costs of travelling one extra kilometre to the beach based on the volumes of trip taken by central city and beach-side residents respectively. Thus, (17) asserts the marginal cost of job commuting one extra kilometre must lie between these upper and lower limits.

The double condition (17) is quite stringent. It can be expected to define a fairly narrow range of values

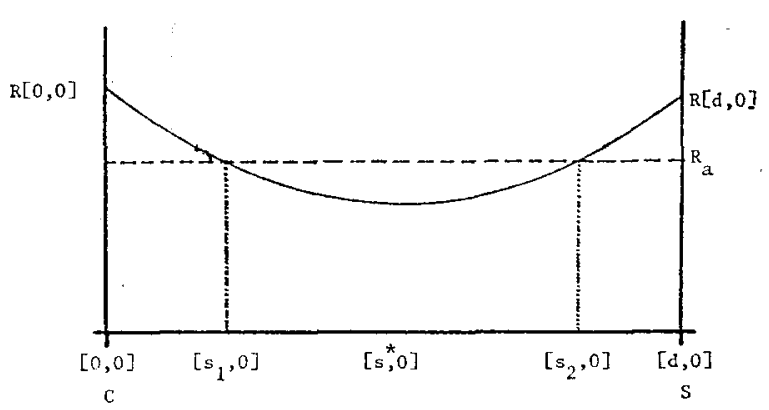

Fig. 7. Nucleated suburbanisation in the Suburban Amenities model.

within which the marginal commuting cost must lie. Planners who would rely on market forces to produce nucleated suburbanisation by merely supplying a local amenity are thus depending on some quite special conditions being met.

\section{Conclusions}

Two spatial equilibrium models are developed in this paper to illustrate some conditions under which nucleated suburbanisation occurs as a consequence of competitive market behaviour. The two models emphasise the tradeoffs involved in the locational choice of residents who are attracted to both suburban and central city sites. Marginal conditions are established under which nucleated suburbanisation is possible. In the job decentralisation model, the marginal cost of job commuting must exceed the marginal cost of travel to the central city for the acquisition of its goods and services. In the suburban amenity provision model, the marginal cost of job commuting must lie between the marginal costs of travel to the suburban amenity as measured from city and suburban centres respectively.

In concluding, some cautionary notes are in order. First, planners have been assumed to rely on only one kind of drawing card; either jobs or local amenity provision. Clearly, the establishment of nucleated suburbs is more likely to occur the more self-contained a suburban area is. The emphasis here on incomplete provision reflects a common situation which planners find themselves unable to create as many suburban jobs or amenities as they would like to.

Also, in this paper, a static view of the world is presented in which the number of jobs or the amenity attraction of an area does not change. However, an area which initially develops because of a residential amenity may subsequently experience a growth in industry and employment as well. This would tend to encourage nucleated suburbanisation by making the suburb more self-contained over time.

Finally, by assuming that all residents are identical, the differences between urban and suburban populations have been ignored. For example, in the beach model, nucleated suburbanisation occurs, albeit under stringent 
conditions, when all residents share the same utility function. If one admits several cohort groups of residents each with different preferences for $X$ versus $L$ consumption, then the likelihood of nucleated suburbanisation might be greatly enhanced. Similarly in the job decentralisation model, it is commonly argued that people attracted to suburban jobs have (or develop) different preferences from central city workers.

\section{REFERENCES}

Field, B. C., and ConRad, J. M. (1975). Economic issues in programs of transferable development rights. Land Economics, Vol. 51: 331-340.

Goldberg, M. A., and Heaver, T. D. (1970). Evaluating transport corridors: an economic model, Journal of Transport Economics and Policy, Vol. 4: 255-264.

MCMILLAN, M. (1974). Open space preservation in developing areas: an alternative policy. Land Economics, Vol. 50: 410-418.

Mrron, J. R. (1976). City size and land rents. In G. Papageorgiou (ed.), Mathematical Land Use Theory, pp. 79-95. Lexington, Mass.: D. C. Heath.

Solow, R. M. (1973). On equilibrium models of urban location. In M. Parkin (ed.), Essays in Modern Economics, pp. 2-16. London: Longman.

VARAIYA, P., and ARTLE, R. (1972). Locational implications of transactions costs. Swedish Journal of Economics, Vol. 73: 174-184.

WhEATON, W. C. (1974). A comparative static analysis of urban spatial structure. Journal of Economic Theory, Vol. 9: 223-237. 